\title{
Novel Incremental Sheet Forming System with Tool-Path Calculation Approach
}

\author{
Imre Paniti ${ }^{1}$, János Somló ${ }^{2}$ \\ ${ }^{1}$ Institute for Computer Science and Control, Hungarian Academy of Sciences, \\ Kende u. 13-17, H-1111 Budapest, Hungary, imre.paniti@sztaki.mta.hu \\ 2 Óbuda University, Bécsi út 96/B, H-1034 Budapest, Hungary, \\ somlo@uni-obuda.hu
}

Abstract: Incremental Sheet Forming (ISF) is a prosperous forming technique since the end of the $20^{\text {th }}$ Century. Research projects are still active in this topic with the goal to understand more deeply this flexible process and to reach the full industrialisation of it. These investigations are mainly focusing on the one-side version of ISF, however only the two side variants of this process could reach the ultimate flexibility. This paper gives an overview of the recent results and inventions in the field of ISF processes. A new solution of the Two-Sided ISF processes realisation is given. A new approach to the tool-path calculation is outlined which is based on a recently patented system of the authors.

Keywords: incremental sheet forming; die-less forming; tool-path calculation; new solution of the Two-Sided ISF

\section{Introduction}

One of the early sheet metal forming processes used at large scale is spinning. This process is suitable for the manufacturing of rotational parts in low and medium large series. Today, a new technology aroused. This is the Incremental Sheet Forming (ISF) or also called as Asymmetric Incremental Sheet Forming (AISF) process. This is in some respect similar to spinning [1], [2], [3].

ISF can be grouped into two main groups, depending on the number of contact points between sheet, tool and die [4]. The term Single Point Incremental Forming (SPIF) is used when the bottom contour of the part is supported by a backing/faceplate. In SPIF the forming tool is pressing contours from the outside inwards, moving the inner flat area of the blank gradually downwards.

The term Two Point Incremental Forming (TPIF) is used when a full or partial die is present to support the sheet. In TPIF the blank holder is moving downwards with the forming tool or the die is moving upwards while the forming tool is pressing the sheet on it (see Figure 1). 


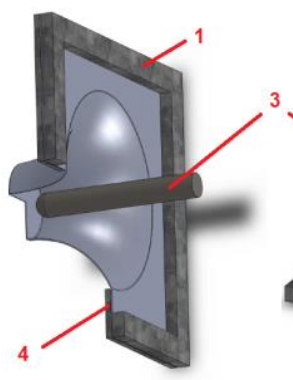

(a)

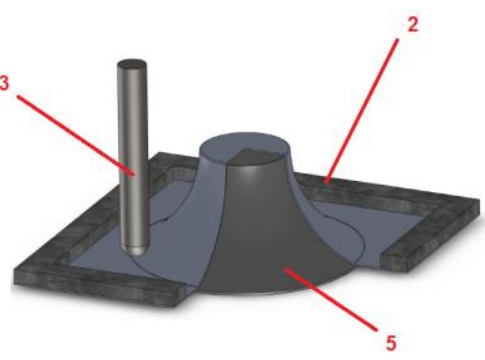

(b)

Figure 1

SPIF (a) in a vertical alignment and TPIF (b) in a horizontal alignment with 1: stationary blank holder,

2: moving blank holder, 3 : forming tool, 4 : backing plate, 5 : stationary or moving full or partial die

A special TPIF variant is the two-sided Incremental Sheet Forming or fully kinematic ISF (with supporting tool) [5], which is more flexible but needs synchronised motion of the forming tools. In the following chapters we will discusses the different types of the two-sided ISF (TSISF), the tool-path calculation approaches for the process, a general description of it, and the novel solution of TSISF with a particular example. Furthermore, a tool-path calculation approach of the suggested system is also presented.

\section{TSISF Systems}

In the previous decades a development of flexible forming technologies (particularly in ISF) could be observed which manifested itself in a number of patents and research projects [6], especially in Europe, in Japan and in the United States.

By analysing the main variants of ISF, it can be seen that SPIF has several limitations compared to two-sided ISF; for example it needs a face-/backing plate, and the forming of convex and concave parts on the same sheet is only feasible if the blank holder is released.

A process with one controller for two synchronised forming tools, with at least three degrees of freedom, corresponding to movements according to axes $\mathrm{X}, \mathrm{Y}$ and $\mathrm{Z}$, can be found in the patented solution of Rodriguez Gutierrez et al. (TECNALIA) [7].

A prototype of this invention, based on a parallel kinematic machine (PKM) and a coordinate table, can be seen in Figure 2. 

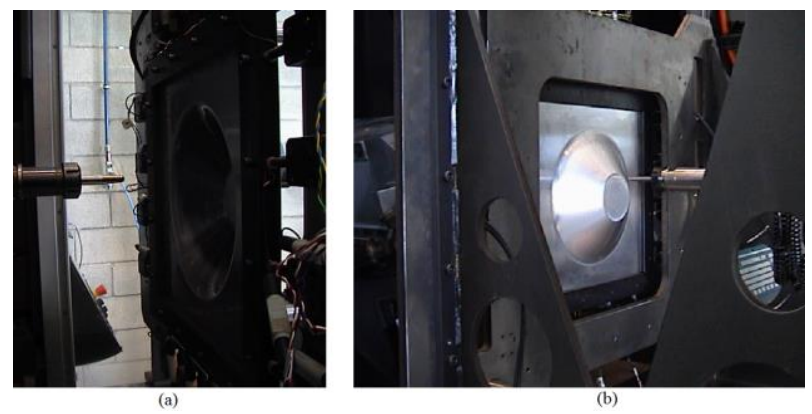

Figure 2

Two-sided Incremental Forming machine of TECNALIA from (a) PKM side and from (b) coordinate table side

This variant is also characterised in that it comprises the continuous detection of the stresses on the sheet due to the movement of the forming tools and the actuation on the means of fastening to alter the gripping force thereof, according to the stresses detected.

In the year of 2012, Carl Frederick Johnson et al. patented a similar method and system in Ford Global Technologies [8]. Figure 3 shows a side view of an exemplary system which can be identified with the set-up of the Ford Freeform Fabrication Technology (F3T).

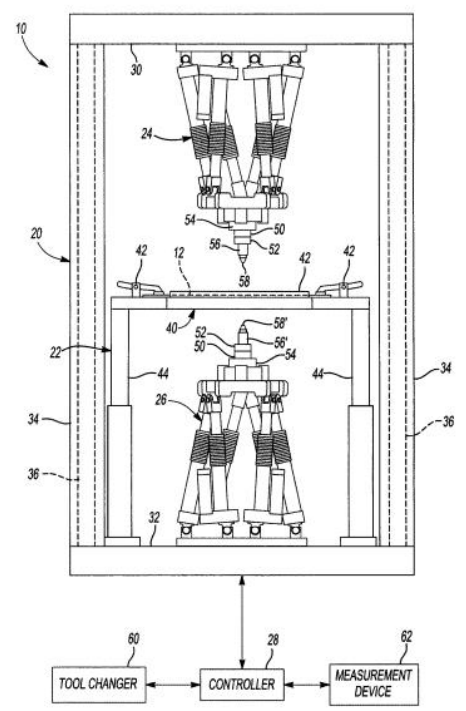

Figure 3 [8]

Side view of Ford's patent variant 
This process variant, like in [9] is an obvious extension of TPIF. However, a synchronised control needs additional sensors and is expensive. A set-up, socalled "Dyna(mic)-Die" has been suggested by Franzen et al. [10] but it is restricted to rotational symmetric motions and needs a synchronised control, too.

According to Yongjun Wang et al. [11] Double Sided Incremental Forming (DSIF) requires two forming tools opposing one another and moving simultaneously on both sides of a sheet metal. The device consists of a $\mathrm{C}$ frame mounted on the spindle saddle of a CNC machine and the tool heads are mounted on the top and bottom bases of the $\mathrm{C}$ frame. The drawback in this case is that a $\mathrm{C}$ frame mounted on the spindle saddle of a CNC machine is limiting the workspace and therefor the freedom of the forming.

The main problem with the previously mentioned devices is that the movement of the lower tool may be influenced by the forces acting on the arm holding the tool and the desired accuracy of the forming may not always be achieved.

The load on the mount frame or other means holding the forming tools may be more, than $1 \mathrm{kN}$ (depending on the desired geometry, the material and the thickness of the sheet), and it is rather difficult to keep the exact position of the tools.

Therefore, the object of the present work is to eliminate the above drawback and to provide a device for two sided incremental sheet forming, which can ensure an accurate forming of sheet materials by stabilised and reliable guiding of the forming tools [12].

\subsection{Forming Strategies in TS-ISF}

Forming experiments on the prototype of TECNALIA showed that the system allows two main forming strategies (see Figure 4) for the manufacturing of sheet metal parts. Furthermore the moving local support of the second tool gives better results in terms of formability [13].

In the case of "strategy A: peripheral support" the second tool acts as a backing plate, moving synchronised with the first tool, but it does not leave the first contour level of the supporting tool-path. In the case of "strategy B: local support" the second tool moves synchronised with the forming tool, but ensuring continuous local support at each tool-path level.

The thinning of the sheet in ISF is usually estimated (with a raw approximation) by means of the sine-law (1), originated from the metal spinning process [14];

$$
t=t_{0} \sin \left(90^{\circ}-\beta\right)
$$

In (1) the parameter $t_{0}$ is the initial thickness of the sheet and $\beta$ is the wall/draw angle, defining the angle between the un-deformed and the deformed part of the sheet. 


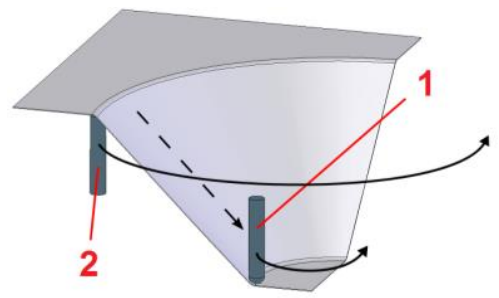

(a)

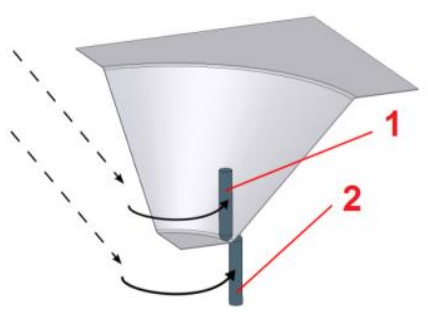

(b)

Figure 4

(a) "strategy A: peripheral support", (b) "strategy B: local support" where 1: forming tool, 2: supporting tool

Maidagan et al. [15] defined the tool configuration for the forming strategy with local support (see Figure 5) and created the equation (2).
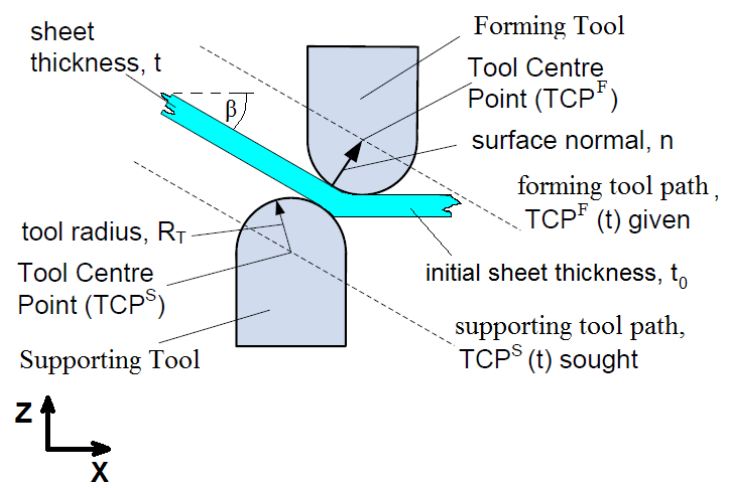

Figure 5

Tool configuration for the forming strategy with local support

$S=F+\left(2 R_{T}+t\right) \frac{\underline{n}}{|\underline{n}|}$

where

$\mathrm{S}=\left[\begin{array}{c}\mathrm{TCP}_{\mathrm{X}}^{\mathrm{S}} \\ \mathrm{TCP}_{\mathrm{Y}}^{\mathrm{S}} \\ \mathrm{TCP}_{\mathrm{Z}}^{\mathrm{S}}\end{array}\right], \quad \mathrm{F}=\left[\begin{array}{c}\mathrm{TCP}_{\mathrm{X}}^{\mathrm{F}} \\ \mathrm{TCP}_{\mathrm{Y}}^{\mathrm{F}} \\ \mathrm{TCP}_{\mathrm{Z}}^{\mathrm{F}}\end{array}\right], \quad$ and $\quad \underline{\mathrm{n}}=\left[\begin{array}{c}n_{X} \\ n_{Y} \\ n_{Z}\end{array}\right]$

As it is clear, here (in Figure 5) the y coordinates are not manipulated $\left(n_{y}=0\right)$. The normal vector $\underline{n}$ can be calculated from a generic tool path, which contains the Tool Centre Point and the contact point. 
Paniti in [16] adapted the equation (2) to simple rotational symmetric parts and defined the following equation for the forming strategy with peripheral support;

$$
\mathrm{S}=\left[\begin{array}{cc}
T C P_{X}^{F} & \frac{R}{r} \\
T C P_{Y}^{F} & \frac{R}{r} \\
T C P_{Z}^{S}
\end{array}\right]
$$

where $T C P_{Z}^{S}$ is calculated only for the first level of the forming. The parameter $r$ is the radius of the last tool-path contour of the forming tool, while $R$ is the radius of the first tool-path contour of the supporting tool. Detailed description with explanatory figures of this adaptation can be found in [16].

The same forming strategies were applied by Meier et al. [17], [18] with two synchronised industrial robots (see Figure 6 and Figure 7), like in a previous European Patent [19] which discloses various configurations, including the use of two robots which needs synchronised control. They also observed better results with the "strategy B: local support"; however their names for the abovementioned strategies were "duplex incremental forming with peripheral support" (DPIF-P) and "duplex incremental forming with local support" (DPIF-L) respectively [18].

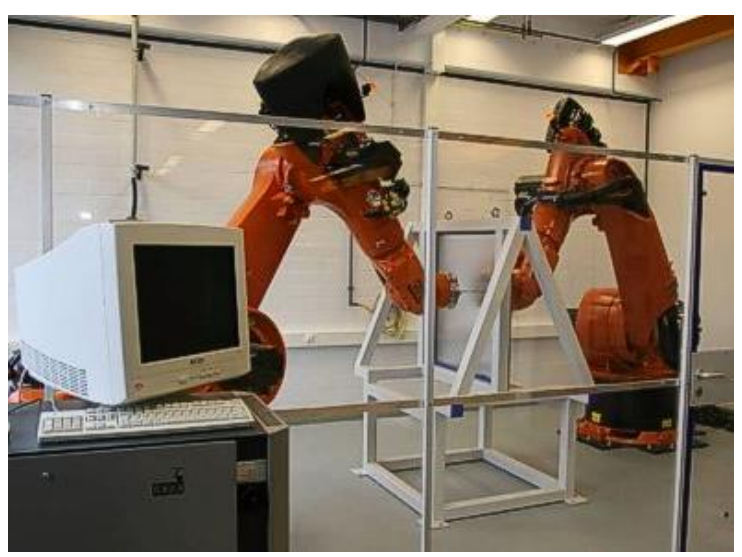

Figure 6 [20]

Two-sided Incremental Forming with synchronised KUKA robots 


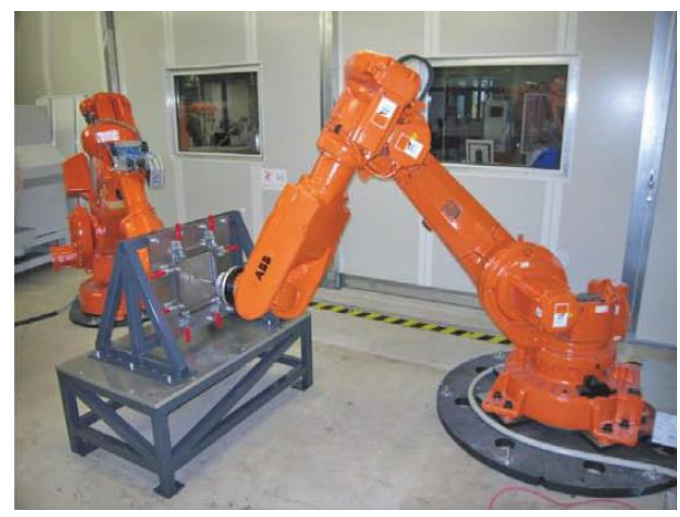

Figure 7 [21]

Two-sided Incremental Forming with synchronised ABB robots

Meier et al. [18] extended the analytical model of Silva et al. [22] for rotational symmetric SPIF with the so called "superimposed pressure" induced by the supporting tool to analyse the influence of the parameters in forming strategy " $\mathrm{B}$ " with local support. They found that superimposed pressure increases the formability in case an optimal supporting contact position (see Figure 8) and optimal force is applied.

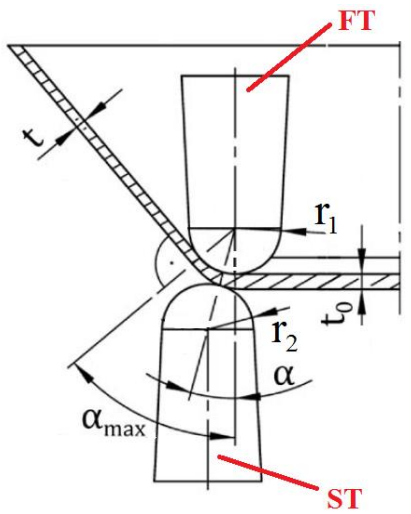

Figure 8 [20]

Contact position of the Supporting Tool (ST) in the localised plastic zone, where FT: Forming Tool, $\alpha$ : shifting angle of the ST, amax: maximum shifting angle of the ST, t: sheet thickness of the deformed sheet, $\mathrm{t}_{0}$ : initial sheet thickness

They introduced a shifting angle $\alpha$ and highlighted that the relative position of the ST to the FT can be varied over the idealised two dimensional forming gap. At an angle $\alpha$ of $0^{\circ}$ the two tools are coaxial and facing opposite to each other, like in case of [11]. The maximum shifting angle $\alpha$ is limited by the actual draw angle, so that the force is induced normal to the surface. 
Their experiments showed that a higher angle $\alpha$ leads to an unwanted deformation of the sheet and "the applied force always acts in the direction of the connecting line between both tool centre points" [18]. Experiments were carried out on an aluminium alloy sheet (AlMn99.8) with an optimal shifting angel $\alpha=30^{\circ}$ and optimal contact force equal to $300 \mathrm{~N}$.

Similar results can be reached with the presented solution in this paper, but in contrary to the competitive variants this system does not need to synchronise minimum 3 extra actuators, only one.

\subsection{Two-sided (Die-Less) Sheet Forming Strategy in General}

In Figure 9 a part of the die-less sheet forming system is shown where the upper tool is the forming tool, the lower one is the supporting tool and between them there is the sheet (fixed by blank holders at the sides) to be formed. Both the forming tool and a supporting tool are applied in a 2.5D to 5D forming machine, which is supposed to be used for manufacturing. It can be a milling machine, a robot or some other device. Except for the "CNC Controlled coupling" solutions below, (when a separate robot or CNC machine is needed to move the supporting tool) both tools are controlled by the same CNC.

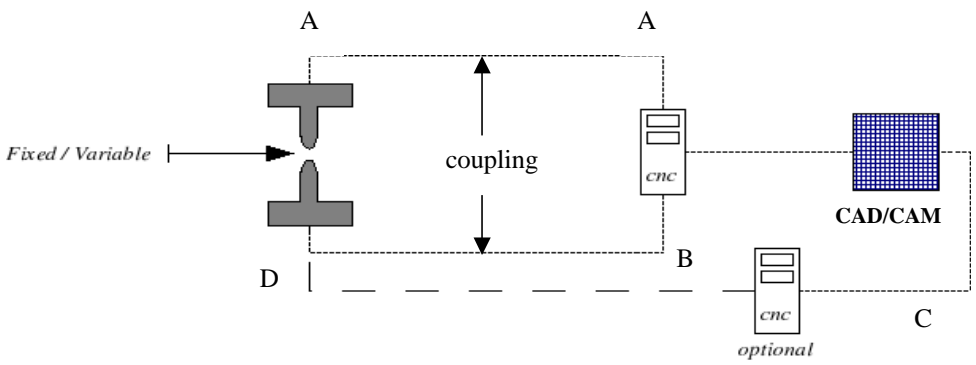

Figure 9

2.5D-5D die-less sheet metal forming

The motion of the forming tool is planned using some proper geometric programming package, CAD/CAM. The package provides CNC program, which is like the one for realising milling process with spherical tool. The forming tool axis should coincide with the normal to the surface in most cases. The axis of the supporting tool can be on the same line as that of the forming tool like in [11].

The connection of the forming and supporting tools may be solved in the following ways:

\section{Fixed, mechanical coupling similar to the device presented in [11]:}

The two tools are allocated using proper turning, rotating, translating mechanical joints at the beginning of the processing. These joints allow turning in the axis direction. A-A-B-D mechanical connection, the $\mathrm{AB} \mathrm{CNC}$ is common for both tools. 


\section{Pressed, mechanical coupling as patented in [12]:}

Similar to case 1 , just the supporting tool is pressed to the surface by spring mechanism or by pneumatic, hydraulic or other device. A-A-B-D mechanical connection, the $\mathrm{AB} \mathrm{CNC}$ is common for both tools.

\section{Controlled, mechanical coupling as patented in [12]:}

Similar to case 2, but the force of the supporting tool is controlled with a proper servo drive implemented in a coupling device. It may be the AB CNC or a device substituting the optional CNC.

\section{CNC Controlled coupling/1:}

The movement and the force of the supporting tool are controlled with a proper, optional CNC (CD CNC). This CNC gets the info from the $\mathrm{AB} \mathrm{CNC}$ and controls a second machine (robot or milling machine). The two CNCs may be connected to give a simple parallel movement to the supporting tool.

\section{CNC Controlled coupling/2:}

The movement and the force of the supporting tool are controlled with a proper, optional $\mathrm{CNC}$ (CD CNC). This CNC gets the info from the $\mathrm{AB}$ CNC plus from measurements (sheet thickness, forces etc.) and controls a second machine (robot or milling machine). Same as case 4, just the optional CNC gets more input info.

Solutions 1., 2. and 3. suppose a fixed or almost fixed mechanical connection between the forming tool and the supporting tool. The forming tool is controlled by a CNC based on CAD/CAM data. We could define solutions 1a., 2a., 3a. where instead of the mechanical connection the control $\mathrm{CNC}$ would control a second machine (robot or milling machine) having the supporting tool. Or even a second (the optional) CNC could be used with the same info as the other CNC and just the sheet material thickness should be taken into account.

Solutions 4. and 5. are more sophisticated and suppose two corresponding, but independent machines with their own controllers for the forming tool and for the supporting tool respectively. If we have the control code for the forming tool, and the CAD-information of the final product we can manage to produce the CNC control code for the supporting tool for every case, when needed.

\section{Description of the New TSISF System}

The blank holder is mounted on support rods standing on a base plate. The upper forming tool is moved in $\mathrm{X}, \mathrm{Y}$ and $\mathrm{Z}$ directions, according to the programmed tool-path. The lower forming tool is copying the $\mathrm{X}$ and $\mathrm{Y}$ motion of the upper forming tool. This motion is realised with a mechanical movement copying device (MMCD), but differently from conventional solutions like in [11], the lower 
forming tool has a motion in $\mathrm{Z}$ direction not together with the copying device but using some linear actuator (mechanic, pneumatic, hydraulic, electrical or the combination of those).

This linear actuator is fixed on a transfer unit, which holds the lower forming tool at standard height with respect to the base plate. The transfer unit in its simplest solution has two degrees of freedom, corresponding to movements according to axes $\mathrm{X}$ and $\mathrm{Y}$, on a base plate.

The reaction force in the $\mathrm{Z}$ direction acting on the lower forming tool and consequently on the linear actuator from the pressing of the sheet is transferred to the base plate through the transfer unit.

The moving device is preferably passive motion equipment and allows free motion in the X-Y plane, and can stabilise the movement of it. A stabiliser may be constructed according to provide e.g. two rotational motions, one rotation and one translation motion or translation motion in $\mathrm{X}$ and $\mathrm{Y}$ direction.

The lower forming tool mounting can be stiff, compliant, or regulated. According to a preferred set-up, there is a link mechanism or a lever transmission between the base plate and the transfer unit.

The MMCD may be a mount frame, having a $\mathrm{C}, \mathrm{O}$ or $\mathrm{U}$ shape, or may be a spindle-gear or a belt-pulley slide mechanism.

To better understand the system characteristics, according to preferred practical set-ups thereof, there is a set of illustrative drawings below (see Figure 10 and Figure 11) to the detailed description.

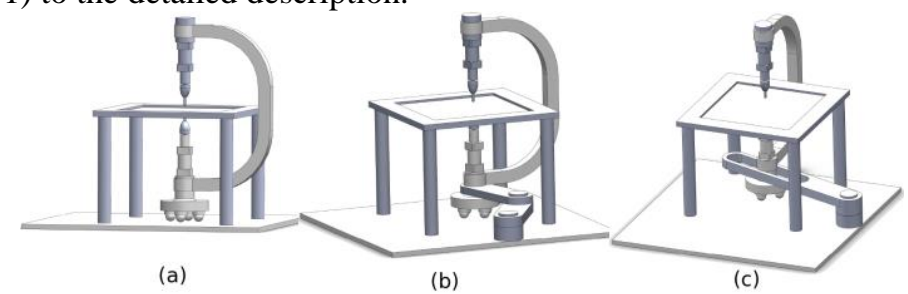

Figure 10

Variants of the TSISF device for small dimensions (a: without stabiliser mechanism, b: with a rotational stabiliser mechanism, c: with a rotational and translational stabiliser mechanism).

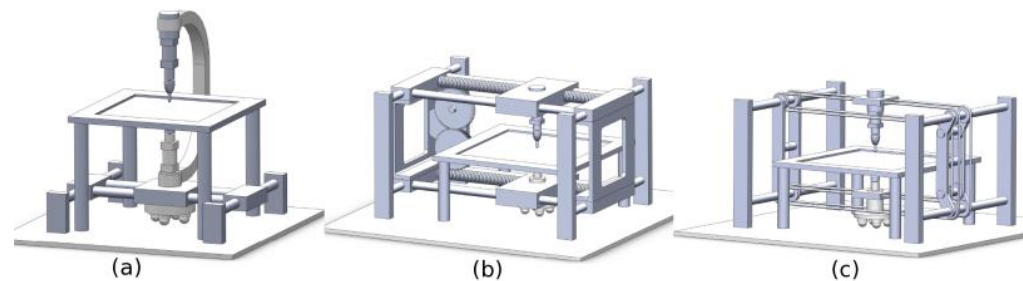

Figure 11

Variants of the TSISF device for large dimensions (a: with linear slides, b: with spindle-gear movement transmission elements, c: with belt-pulley slide mechanism) 
This TSISF system enables safe and exact movement of the forming tools without applying sophisticated and expensive constructions. The system elements for moving the lower forming tool on the surface of the base plate, e.g. a transfer unit with rolling balls eliminates the non-desired movement of the forming tools in the direction of the load. The system can easily be mounted and dismounted, and therefore it is especially applicable for producing pieces with complex part geometry even in small series [12]. The proposed TSISF system can be applied as an external axis in some 4D milling machine centres and in robotic cells, too.

\section{Realisation of the TSISF System with Linear Slides and Force Control}

In order to test a selected variant of the TSISF an experimental system was designed. Figure 12 shows the CAD model of a set-up, similar to the variant presented in Figure 11a.

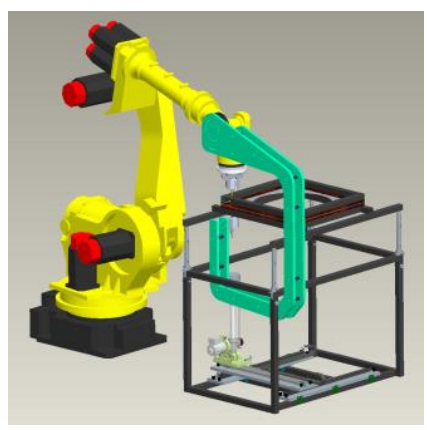

Figure 12

3D model of the set-up with a Fanuc S430iF type industrial robot

The form of the $\mathrm{C}$-frame is designed to secure the linear actuator against radial forces. FEM simulations have been made in ANSYS with radial forces up to 600 $\mathrm{N}$ (see Figure 13) based on previous forming experiments (SPIF of $5 \mathrm{~mm}$ thick polyethylene sheets) to validate the $\mathrm{C}$-frame design.

Results of the FEM simulation showed tolerable stresses below $87 \mathrm{MPa}$ in the rib elements. The C-frame is mounted on a FANUC S430iF type industrial robot's $5^{\text {th }}$ axis. The movement of the upper forming tool (which preferred to be mounted eccentric to the axis of the $6^{\text {th }}$ joint of the robot) is realised with a FANUC R-J3 controller. The eccentric mounting allows the realisation of the optimal contact position discussed in chapter 2.1. 


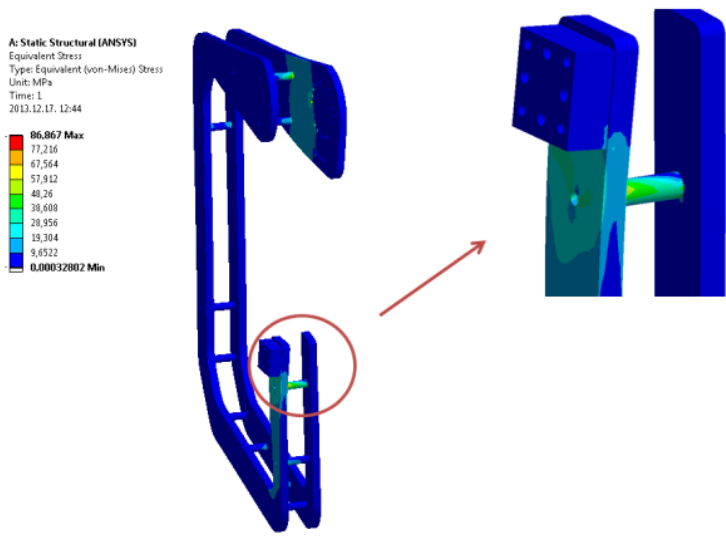

Figure 13

FEM simulation of the C-frame

Both forming tools are mounted on a CLS1000 type measurement cell to give a force feedback to the TSISF control and to ensure an optimal contact force. In this case only the highest component ( $\mathrm{z}$ ) of the reaction force is measured. The linear motion of the lower forming tool is realised with a BSA 20 type ball screw linear actuator with rotational encoder. High level motion commands are sent from the R-J3 controller to the robot and to the linear actuator, too.

\subsection{Trajectory Planning}

One of the most important problems to be solved at the use of such a new kind of material processing principles and systems is the development of proper process planning methods. Among other problems, trajectory planning (determination of velocities along the paths) should have an effective solution. It seems to us that approaches used at metal processing by machine tools in general can be used as basis for this technology, too (see for example:[23]).

A mathematical model for cutting processes proposed in [23], consist from 3 parts:

1.) System of constraints

2.) Performance index

3.) Tool life equation

In the case of incremental sheet metal forming the tool life issues are less important (but not negligible). So, the determination of the optimal regimes becomes rather simple. It seems that at given depth, maximum feed values should be used. These are determined by the system of constraints. But, the determination of the constraints becomes a new and rather complicated problem. To the first plan the dependence of the surface quality on feeds and also temperatures moves. 
Very promising opportunity is the application of high velocity processing. For that an important issue is the realisation of time optimal cruising motion on the given paths. These problems are solved and published in Somlo, Lantos, Cat [24]. The time-optimal cruising trajectory planning supposes that the forming tool passes any length on a given path for minimum time. The knowledge of the limit values opens opportunity for effective utilisation for given equipment (robot).

\subsection{Tool-Path Calculation Approach for Concave and Convex Surfaces without Releasing the Blank Holder}

In case an eccentric upper tool is applied in TSISF, the following tool-path calculation method is proposed;

When the eccentric tool (mounted on the machine) is acting as forming tool, while the supporting tool on the linear actuator is force controlled:

1. Calculate generic tool-path GTP(X, Y, Z, I, J, K) of the part as in SPIF

(I, J, K values are coordinates of the contact point).

2. Calculate supporting points with equation (2).

3. Replace Z coordinates in (2) from GTP for eccentric tool-path.

4. Calculate rotational angle $\gamma$ of the last joint based on the following coordinates: $\mathrm{TCP}_{\mathrm{X}}^{\mathrm{F}}, \mathrm{TCP}_{\mathrm{Y}}^{\mathrm{F}}, \mathrm{TCP}_{\mathrm{X}}^{\mathrm{S}}, \mathrm{TCP}_{\mathrm{Y}}^{\mathrm{S}}$.

5. Solve inverse kinematics problem.

6. Replace the joint position value of the last joint to $\gamma$.

When the eccentric tool (mounted on the machine) is acting as supporting tool, the Z-coordinate of it is force controlled and the linear actuator is acting as forming tool:

1. Calculate generic tool-path $\operatorname{GTP}(\mathrm{X}, \mathrm{Y}, \mathrm{Z}, \mathrm{I}, \mathrm{J}, \mathrm{K})$ of the part as in SPIF

(I, J, K values are coordinates of the contact point).

2. Recalculate $\mathrm{Z}$ for linear actuator, based on starting position of the actuator.

3. Calculate supporting points with equation (2).

4. Calculate rotational angle $\gamma$ of the last joint based on the following coordinates: $\mathrm{TCP}_{\mathrm{X}}^{\mathrm{F}}, \mathrm{TCP}_{\mathrm{Y}}^{\mathrm{F}}, \mathrm{TCP}_{\mathrm{X}}^{\mathrm{S}}, \mathrm{TCP}_{\mathrm{Y}}^{\mathrm{S}}$.

5. Solve inverse kinematics problem.

6. Replace the joint position value of the last joint to $\gamma$.

The inverse kinematics problem can be solved with conventional methods (numerically, simulated) or directly by the recording of the joint positions during a 
test execution of the GTP without forming the sheet. The eccentricity of the upper forming tool is pre-defined by equation (1). In case the part geometry contains more than one wall angel, the eccentricity have to be adjusted to it.

\section{Experimental Results}

Experiments have been carried out on a TSISF prototype and on a robotic cell to compare the results with a simplified SPIF. Both set-ups excluded the use of a backing plate. The TSISF prototype formed a truncated cone (see geometry in Figure 14) while the robotic cell created a truncated pyramid (see geometry in Figure 15). Both geometries are commonly used to test the forming limits of Incremental Sheet Forming. Aluminium sheets (Al 1050) with $0.5 \mathrm{~mm}$ and 0.6 $\mathrm{mm}$ initial thickness were selected with forming speed $50 \mathrm{~mm} / \mathrm{sec}$ and 300 $\mathrm{mm} / \mathrm{sec}$. A proper lubrication was used during the experiments. Forming tools with $10 \mathrm{~mm}$ tool diameter were selected in both cases.

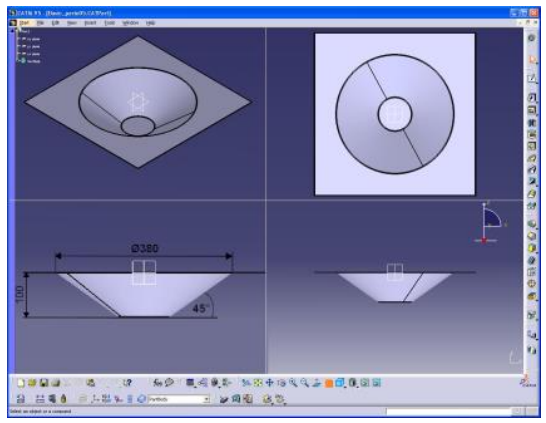

Figure 14

Truncated cone geometry with wall angle $\beta=45^{\circ}$ in a CATIA CAD program

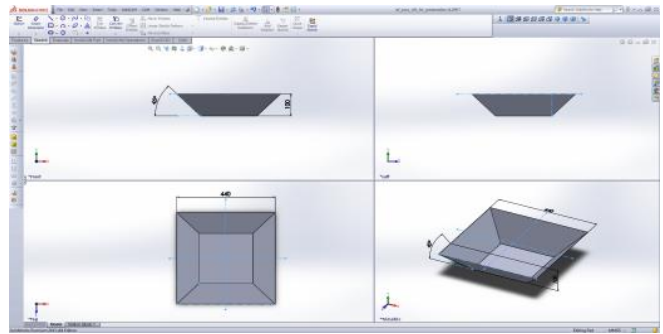

Figure 15

Truncated pyramid geometry with wall angle $\beta=45^{\circ}$ in a SolidWorks CAD program 
Figure 16 and Figure 17 show the results of the TSISF experiment, while Figure 18 and Figure 19 represent the results of the simplified SPIF process.

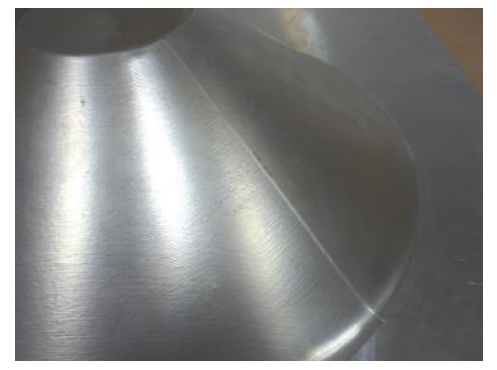

Figure 16

Final part made with TSISF

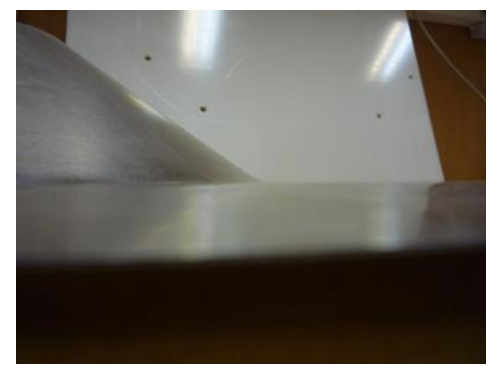

Figure 17

Peripheral area on the final part made with TSISF

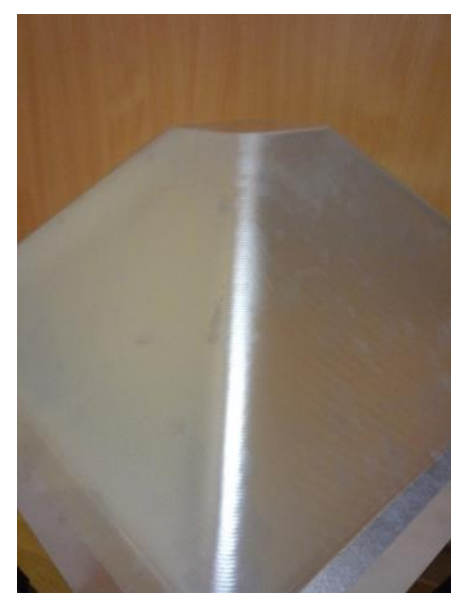

Figure 18

Final part made with SPIF 


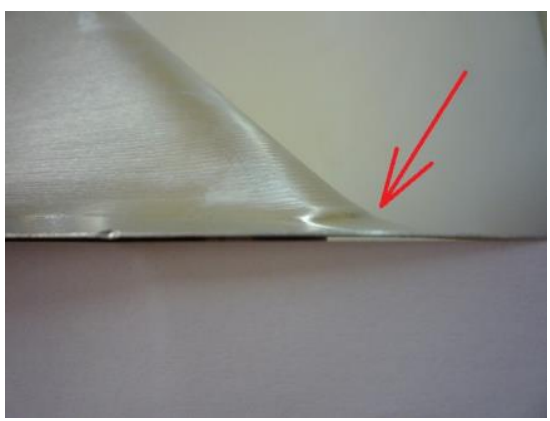

Figure 19

Peripheral area on the final part made with SPIF with unwanted deflection

No deflection can be seen at the peripheral area on the final part made with TSISF contrary to SPIF where unwanted deflection can be monitored.

\section{Conclusions}

A novel Two Sided Incremental Sheet Forming (TSISF) system was presented which can be described as a cost efficient fully kinematic ISF solution. Motion and Finite Element Method simulations proved that the proposed TSISF concept with a C-frame is suitable for creating concave and convex shapes without the release of the sheet. The presented tool-path calculation approach showed that the eccentric mounting of the upper tool allows the realisation of an optimal contact position in TSISF, however the eccentricity have to be adjusted in case of different drawing angles.

\section{Acknowledgement}

This work was supported by the Institute for Computer Science and Control, Hungarian Academy of Sciences (MTA SZTAKI).

\section{References}

[1] Edward Leszak (1967): Apparatus and Process for Incremental Dieless forming, US Patent US3342051

[2] Berghahn Walter G, Murray Jr George F (1967): Method of Dielessly Forming Surfaces of Revolution, US Patent US3316745

[3] Izeki, Hideo; Kamiide, Takuo; Shimoda, Naoki (1998): Tool Unit for Sequential Stretch Forming and Sequential Stretch Forming Machine, Japanese Patent JP10-180365

[4] Hirt, G.; Ames, J.; Bambach, M.; Kopp, R. (2004): Modeling and Experimental Evaluation of the Incremental CNC Sheet Metal Forming Process, CIRP Annals - Manufacturing Technology, Vol. 53, No. 1, pp. 203-206 
[5] Tekkaya, A. Erman, ed. Sheet Metal Forming: Processes and Applications, Asm International, 2012

[6] Emmens, WC; Sebastiani, G; van den Boogaard, AH (2010): The Technology of Incremental Sheet Forming - a Brief Review of the History, J. of Material Processing Technology 210(8):981-997, doi:10.1016/j.jmatprotec.2010.02.014

[7] Gutierrez Pedro Pablo Rodriguez, Rastrero Maria Asuncion Rivero, Onandia Elixabete Maidagan (2008): Machine for Shaping Sheet Metal and Shaping Method, PCT Patent EP1977842

[8] Carl Frederick Johnson, Vijitha Senaka Kiridena, Feng Ren, Zhiyong Cedric Xia (2012): System and Method for Incrementally Forming a Workpiece, US Patent US8322176

[9] Shima, Akio; Yoshikawa, Takenao; Nakamura, Keiichi; Sudo, Yoichi; Suzuki, Shoji (1997): Formation of Successively Expanding Metallic Plate and Apparatus Therefor, Japanese Patent JP09-085355

[10] Franzen, V., Kwiatkowski, L., Sebastiani, G., Shankar, R., Tekkaya, A. E., Kleiner, M. (2008): Dyna-Die: Towards Full Kinematic Incremental Forming, Proceedings Esaform, Lyon, France, April 23-25 2008, paper \#302

[11] Yongjun Wang, Ying Huang, Jian Cao (2008): Experimental Study on a New Method of Double Side Incremental Forming, in the Proceedings of ASME 2008 Conference, October 7-10, 2008, Evanston, Illinois, USA, pp. 601-607

[12] Imre Paniti, Janos Somlo (2013): Device for Two-sided Incremental Sheet Forming, EU Patent EP2505279

[13] Tisza, M.; Paniti, I.; Kovács, P. Z. (2010): Experimental and Numerical Study of a Milling Machine-based Dieless Incremental Sheet Forming, International Journal of Material Forming, Volume 3, Supplement 1, pp. 441-446

[14] Avitzur, B.; Yang, C. T. (1960): Analysis of Power Spinning of Cones, Journal of Engineering for Industry. Transactions of ASME, Ser. B 82, 1960, pp. 231-245

[15] Maidagan, E., Zettler, J., Bambach, M., Rodríguez, P. P., \& Hirt, G. (2007): A New Incremental Sheet Forming Process Based on a Flexible Supporting Die System, Key Engineering Materials, 344, pp. 607-614

[16] Paniti, Imre (2010): CAD API-based Tool-Path Control for Novel Incremental Sheet Forming, Pollack Periodica, 5 (2). pp. 81-90

[17] Meier, Horst, B. Buff, and V. Smukala (2009): Robot-based Incremental Sheet Metal Forming-Increasing the Part Accuracy in an Automated, Industrial Forming Cell, Key Engineering Materials 410 (2009): 159-166 
[18] Meier, H.; Magnus, C.; Smukala, V. (2011): Impact of Superimposed Pressure on Dieless Incremental Sheet Metal Forming with Two Moving Tools, CIRP Annals - Manufacturing Technology, Volume 60, Issue 1, 2011, pp. 327-330

[19] Timo Tuominen (2005): Method and Apparatus for Forming ThreeDimensional Shapes in a Sheet Metal, PCT Patent EP1560668

[20] Roboforming Project Documentation, Incremental Sheet Forming with two KUKA robots, http://www.lps.ruhr-unibochum.de/ausstattung/labor/roboforming/, available online in Febr. 2014

[21] Roboforming Project Documentation, ISF with two ABB robots, http://www.dieffenbacher.de/fileadmin/bilder/Sonstiges/Broschueren_PDFs /Forschung_Entwicklung/bericht_roboforming_de.pdf, available online in February 2014

[22] Silva, M. B.; Skjoedt, M.; Martins, P. A. F.; Bay, N. (2008): Single-Point Incremental Forming and Formability-Failure Diagrams, Journal of Strain Analysis for Engineering Design, 43/1 (2008), pp. 15-36

[23] Horváth M., Somló J. (1979): Optimization and Adaptive Control of Manufacturing Processes (In Hungarian) Müszaki kiadó, Budapest, p. 260

[24] J. Somló, B. Lantos, P. T. Cat (1997): Advanced Robot Control, Academy Press, Budapest, p. 425 